\title{
Investment Income of US Nonprofit Hospitals in 2017
}

J Gen Intern Med 35(9):2818-20

DOI: $10.1007 /$ s11606-020-05929-5

(C) Society of General Internal Medicine 2020

\section{INTRODUCTION}

Nonprofit hospitals play a primary role in providing hospital services to Americans. ${ }^{1}$ Their financial viability has important implications for access to hospital care and the competitiveness of the hospital market. ${ }^{2}$ Nonprofit hospitals often generate investment income-such as interest revenue, dividends, rental income, gain or losses on sale of investment assets - to diversify revenue sources and enhance their financial position. ${ }^{3,}{ }^{4}$ To date, nonprofit hospitals' investment income has remained unexplored in the literature. The recent outbreak of COVID-19 significantly increased the volatility of global financial markets. In this study, we examined the magnitude and distribution of US nonprofit hospitals' investment income in 2017 and analyzed the implications on hospitals' financial position. Based on the findings, we discussed the potential impact of financial market volatility on nonprofit hospitals' investment income and financial viability.

\section{METHODS}

2017 Hospital Cost Reports published by the Centers for Medicare and Medicaid Services were used in the analysis, with 2017 being the latest year for which a complete nationwide data set was publicly available online. ${ }^{5}$ A total of 2590 general short-term nonprofit hospitals located in the USA with non-missing reported net patient revenue were included in the sample. Investment income is one of 18 categories of nonoperating income specified in Cost Reports. Besides the specified non-operating income, hospitals also report unspecified non-operating income.

We first examined the composition of specified nonoperating income and the magnitude of investment income relative to other types of non-operating income. Next, we ranked hospitals based on their investment income and examined the shares of investment income across hospital quartiles and for hospitals in the top $1 \%$ and 5\%. Finally, we compared investment income and

Received April 2, 2020

Accepted May 18, 2020

Published online June 15, 2020 overall net income (i.e., total net income generated from operating and non-operating activities) across these hospital groups to understand the impact of investment income on hospitals' financial position.

\section{RESULTS}

In 2017, all US nonprofit short-term general hospitals reported a $\$ 52.6$ billion non-operating income, consisting of $\$ 34.0$ billion from the unspecified category and $\$ 18.6$ billion from 18 specified categories. Among the $\$ 18.6$ billion of specified non-operating income, investment income ( $\$ 8.0$ billion) is the dominant category (43\%) (Fig. 1).

Among the 2590 nonprofit hospitals in our sample, $1684(65 \%)$ reported positive investment income, 842 (33\%) reported no investment income, and 64 (2\%) reported negative investment income. The top $1 \%$ of hospitals with the highest investment income generated $36 \%$ of the $\$ 8.0$ billion of all investment income of the 2590 hospitals (Fig. 1). The top 5\% of hospitals' investment income accounted for $69 \%$ of all investment income. The top quartile of hospitals earned almost all investment income (98\%).

Investment income substantially contributed to the overall net income for the top quartile of hospitals. Their aggregated overall net income would have dropped by $31 \%$ if they had generated no investment income. For the top $1 \%$ and the top 5\% of hospitals, their aggregated overall net income would have dropped by $46 \%$ and $40 \%$, respectively, if they had generated no investment income. Investment income had a negligible contribution to the aggregated overall net income in the other three quartiles. As a sensitivity test, we examined the median value (rather than the aggregated value) in each category and the results remained qualitatively consistent (Fig. 2).

\section{DISCUSSION}

Investment income provided an important income source for a quarter of US nonprofit hospitals in 2017. Holding other revenues and expenses constant, these hospitals' aggregated overall net income would have dropped by $31 \%$ if they had generated no investment income, and would have dropped by $62 \%$ or nearly disappeared if they had experienced investment loss of the same amount (as the investment income) or twice 


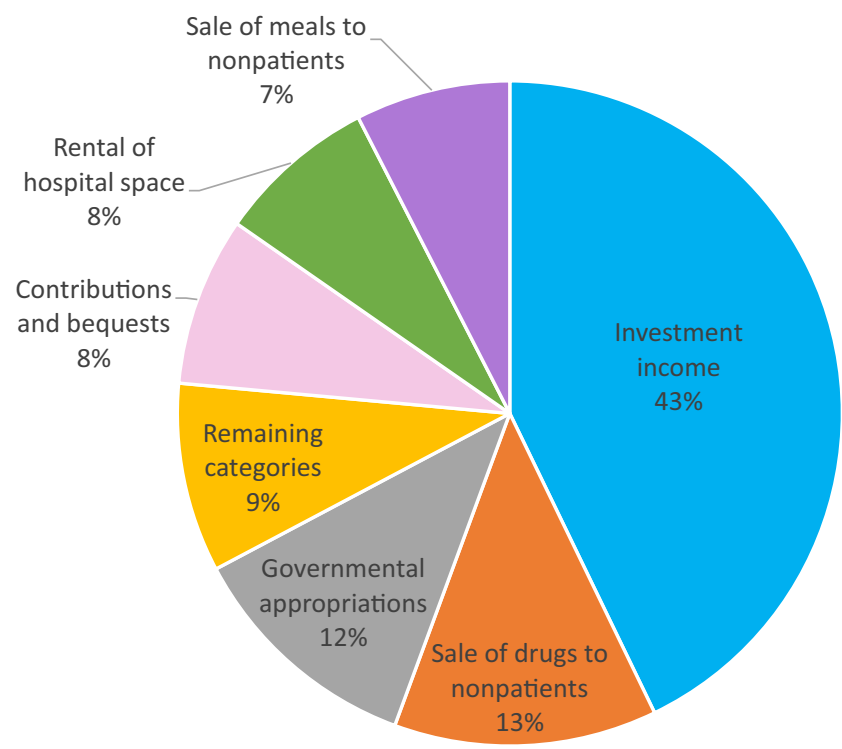

Figure 1 Composition of specified non-operating income of US nonprofit hospitals in 2017. Notes: (1) The aggregated nonoperating income of US nonprofit hospitals in 2017 was \$18.6 billion. (2) "Remaining categories" include tuition (2.5\%), parking lot receipts $(2.1 \%)$, rebates and refunds $(1.6 \%)$, gift shop and canteen $(0.7 \%)$, telephone and communications $(0.6 \%)$, purchase discounts $(0.6 \%)$, rental of living quarters $(0.4 \%)$, sales of medical records and abstracts $(0.2 \%)$, sales of medical and surgical supplies to nonpatients $(0.2 \%)$, rental of vending machines $(0.1 \%)$, TV and radio services $(0.1 \%)$, and laundry and linen services $(0.1 \%)$. the amount, respectively. Investments involve risks linked to the volatility of financial markets. COVID-19 has substantially destabilized global financial markets - for example, it has erased 3 years of gains of the Dow Jones Industrial Average between Feburary 17 and March 20, 2020. ${ }^{6}$ Besides affecting their patient care operations, this pandemic may impose investment income volatility on some nonprofit hospitals that have investments with exposure to the financial markets during that period.

This study was limited by the unavailability of the specific sources and usage of investment income, which prevented analysis of detailed investment behavior and spending decisions. Moreover, the analysis of COVID-19 on patient care operations is beyond the scope of this study.

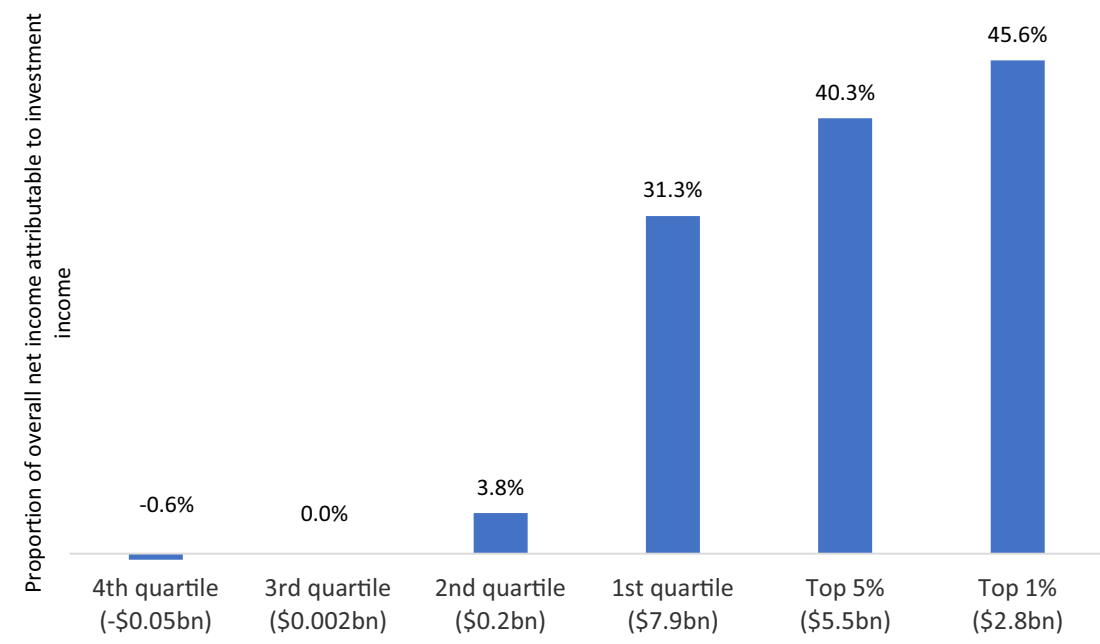

Hospital ranking by investment income

Figure 2 The proportion of overall net income attributable to investment income across US nonprofit hospitals in 2017. Notes: (1) Hospitals were ranked based on their investment income. Top 1\%, top 5\%, 1st quartile, 2nd quartile, 3rd quartile, and 4th quartile represent hospitals ranked 1-26, 1-130, 1-648, 649-1295, 1296-1943, and 1944-2590, respectively. (2) The dollar amounts in parentheses refer to the aggregated investment income in a given group. (3) Overall net income among the top 1\%, top 5\%, 1st quartile, 2nd quartile, 3rd quartile, and 4th quartile is $\$ 6.2 \mathrm{bn}, \$ 13.6 \mathrm{bn}, \$ 25.2 \mathrm{bn}, \$ 5.0 \mathrm{bn}, \$ 8.7 \mathrm{bn}$, and $\$ 9.4 \mathrm{bn}$, respectively. (4) The percentages on the $y$-axis represent the aggregated investment income divided by the aggregated overall net income in a given group. (5) The median ratio of investment income divided by the aggregated overall net income among the top 1\%, top 5\%, 1st quartile, 2nd quartile, 3rd quartile, and 4th quartile is $51.4 \%, 42.6 \%, 24.7 \%, 0.9 \%, 0.0 \%$, and $0.0 \%$, respectively. 
Acknowledgments: We thank Kurt Schaeffler, CPA, for his valuable comments.

Ge Bai, PhD, $C P A^{1,2}$

Farah Yehia, $P h D^{2}$

Wei Chen, $B S^{2}$

Gerard F. Anderson, $P h D^{2}$

${ }^{1}$ Johns Hopkins Carey Business School, Baltimore, MD, USA

${ }^{2}$ Johns Hopkins Bloomberg School of Public Health, Baltimore, MD, USA

Corresponding Author: Ge Bai, PhD, CPA; Johns Hopkins Carey Business School, Baltimore, MD, USA (e-mail: gbai@jhu.edu).

Funding Information All authors received funding from Arnold Ventures.

\section{Compliance with Ethical Standards:}

Conflict of Interest: Ge Bai has provided consulting services for Cohen, Feeley, Altemose, and Rambo regarding some nonprofit hospitals.

\section{REFERENCES}

1. American Hospital Association. Fast facts on U.S. hospitals, 2020. https://www.aha.org/statistics/fast-facts-us-hospitals. Jan 2020. Accessed April 1, 2020.

2. Lindrooth RC, Perraillon MC, Hardy RY, Tung GJ. Understanding the relationship between Medicaid expansions and hospital closures. Health Aff (Milldood). 2018;37(1):111-120. https://doi.org/10.1377/hlthaff.2017. 0976

3. Investments include property, business ventures, and financial instruments, such as bonds, stocks, and other types of marketable securities.

4. White MC. Hospitals made $\$ 21 \mathrm{~B}$ on Wall Street last year, but are patients seeing those profits? https://www.nbcnews.com/business/businessnews /hospitals-made-21b-wall-street-last-year-are-patients-seeingn845176. Feb 7, 2018. Accessed April 1, 2020.

5. Center for Medicare \& Medicaid Services. Cost reports. https://www.cms. gov/Research-Statistics-Data-and-Systems /Downloadable-Public-UseFiles/Cost-Reports. Jan 21, 2020. Accessed April 1, 2020.

6. Yahoo Finance. Dow Jones Industrial Average historical data. https:// finance.yahoo.com/quote/\%5EDJI/history/. Apr 1, 2020. Accessed April 1,2020 .

Publisher's Note: Springer Nature remains neutral with regard to jurisdictional claims in published maps and institutional affiliations. 